\title{
AUMENTO DE LA NATALIDAD EN CHILE: ¿CAMBIO DEMOGRÁFICO DESEABLE?
}

Recientemente un medio periodístico escrito (1) tituló en su edición del 31 de mayo de 2009: "CANTIDAD DE NACIDOS EN PRIMER TRIMESTRE DE 2009 MARCA PEAK DE LOS ÚLTIMOS 8 AÑOS" (1). Esta información deriva de la creciente inscripción de los nacimientos en el Registro Civil, observándose que en 2008 se registraron 257.840 nacimientos, siendo el más alto desde 2004, alza que continua en el primer trimestre de 2009 , rompiendo la tendencia descendente de la natalidad desde 1990.

Esta noticia es reconfortante, especialmente porque la natalidad entre 1990-2004, fue año tras año descendente, alcanzando una baja de $21,2 \%$ en el período, tendencia que es considerada un problema país por la trascendencia que tiene este fenómeno demográfico en las políticas económicas y sociales del país (2). Sin embargo, el descenso de la natalidad, especialmente por el control de la fecundidad en grupos de alto riesgo, ha permitido el control de la mortalidad materna, perinatal e infantil.

Es importante conocer a que se puede atribuir este cambio de tendencia de la natalidad, ya que no se conoce de políticas públicas pronatalidad de corto plazo, solamente la reforma previsional, recientemente promulgada, que establece una asignación económica para la mujer, por cada hijo vivo al cumplir los 65 años (3), siendo muy difícil que actualmente tenga impacto en la natalidad.

Un análisis de la fecundidad en Chile del período 1990-2004, observó que la natalidad descendió significativamente en los grupos etarios de bajo riesgo (20-34 años), con aumento significativo de la natalidad de los grupos de alto riesgo, como son las niñas de 10-14 años y las mujeres de 35-44 años; mientras que las adolescentes de 15-19 años, si bien no redujeron significativamente su fecundidad, aportaron menos nacimientos al descenso general del indicador (4). Todo lo anterior, sumado al envejecimiento poblacional de mujeres en edad fértil, confiere a la población obstétrica chilena un creciente y mayor riesgo materno, perinatal e infantil.

Al momento de este Editorial, el Instituto Nacional de Estadísticas de Chile ha entregado el anuario de Estadísticas Vitales correspondiente al año 2006 (5). Si comparamos el año 2004 (natalidad más baja desde 1990), con los años 2005 y 2006, observamos un discreto aumento de la natalidad general acumulada de 0,45\%. Lamentablemente, la natalidad aumentó en las adolescentes (5,3\% para las menores de 15 años y 9,6\% para las de $15-19$ años) y en mujeres en edad reproductiva avanzada (28,5\% para las mujeres de 45 o más años) (Tabla I). Si esta tendencia se mantiene al 2009, es posible esperar un deterioro de los indicadores de salud materno-infantil. Afortunadamente, entre los años 2004-2006, esto aún no es observable en las tasas de mortalidad infantil y neonatal, pero si se aprecia un preocupante aumento de la mortalidad materna y fetal, mayor riesgo que es característico de las mujeres en edad reproductiva avanzada $(6,7)$ (Tabla II).

El análisis preliminar de las cifras presentadas, permite plantear la hipótesis que se ha producido un descuido del control de la fecundidad en las adolescentes y mujeres mayores, por lo que el aumento de la natalidad en el período 2004-2006, no es el cambio demográfico deseable.

Dr. Enrique Donoso S. Editor Jefe. 
Tabla I

NATALIDAD SEGÚN RANGOS DE EDAD MATERNA, CHILE 2004-2006

\begin{tabular}{crrrc}
\hline $\begin{array}{c}\text { Edad materna } \\
\text { (años) }\end{array}$ & $\begin{array}{c}\text { Año } \\
2004\end{array}$ & $\begin{array}{c}\text { Año } \\
2005\end{array}$ & $\begin{array}{c}\text { Año } \\
2006\end{array}$ & $\begin{array}{c}\% \text { cambio } \\
\text { acumulado }\end{array}$ \\
\hline$<15$ & 905 & 935 & 954 & 5,3 \\
$15-19$ & 33.507 & 35.143 & 36.819 & 9,6 \\
$20-24$ & 53.512 & 54.032 & 54.312 & 1,4 \\
$25-29$ & 54.126 & 53.401 & 52.387 & $-3,2$ \\
$30-34$ & 50.571 & 49.906 & 49.335 & $-2,4$ \\
$35-39$ & 29.108 & 28.810 & 28.767 & $-1,1$ \\
$40-44$ & 8.207 & 8.234 & 8.372 & 2,0 \\
$\geq 45$ & 335 & 370 & 437 & 28,5 \\
ND & 81 & - & - & $\mathrm{NA}$ \\
Total NV & 230.352 & 230.831 & 231.383 & 0,45 \\
\hline
\end{tabular}

ND: no declarado. NA: no aplicable. NV: nacido vivo.

Tabla II

EVOLUCIÓN DE LA MORTALIDAD MATERNA, INFANTIL, NEONATAL Y FETAL, CHILE 2004-2006

\begin{tabular}{ccccc}
\hline Año & $\begin{array}{c}\text { Materna } \\
(\times 100.000 \mathrm{NV})\end{array}$ & $\begin{array}{c}\text { Infantil } \\
(\times 1000 \mathrm{NV})\end{array}$ & $\begin{array}{c}\text { Neonatal } \\
(\times 1000 \mathrm{NV})\end{array}$ & $\begin{array}{c}\text { Fetal } \\
(\times 1000 \mathrm{NV})\end{array}$ \\
\hline 2004 & 17,5 & 8,4 & 5,4 & 6,2 \\
2005 & 19,8 & 7,9 & 5,2 & 7,6 \\
2006 & 19,3 & 7,6 & 5,1 & 8,7 \\
\hline
\end{tabular}

NV: nacido vivo.

\section{REFERENCIAS}

1. Olivares R. Cantidad de nacidos en primer trimestre de 2009 marca peak de los últimos 8 años. El Mercurio, 31 de mayo 2009. Hallado en: http://www.mer.cl/modulos/catalogo/Paginas/2009/05/31/MERSTNA007CC3105.htm

2. Donoso E. Descenso de la natalidad en Chile: un problema país (Editorial). Rev Chil Obstet Ginecol 2007;72:73-5.

3. Gobierno de Chile, Ministerio del Trabajo y Previsión Social. Reforma Previsional. Hallado en: http://www.reformaprevisional.cl/reforma_previsional/inicio/beneficio_3.htm.
4. Donoso E, Carvajal J, Domínguez MA. Reducción de la fecundidad y envejecimiento de la población de mujeres chilenas en edad fértil: 1990-2004. Rev Méd Chile 2009;137:766-73.

5. Instituto Nacional de Estadísticas de Chile. Estadísticas Vitales, 2006.

6. Donoso E, Villarroel L. Edad materna avanzada y riesgo reproductivo. Rev Méd Chile 2003;130:55-9.

7. Donoso E, Carvajal J. Maternal, perinatal, and infant outcome of spontaneous pregnancy in the sixth decade of life. Maturitas 2008;59:381-6. 